\title{
Justiça restaurativa em crimes de violência doméstica contra as mulheres: limites e desafios das experiências brasileiras
}

\author{
Restorative Justice in domestic violence crimes against women: \\ limits and challenges from Brazilian experiences
}

\author{
Rodrigo Ghiringhelli de Azevedo
}

Michelle Karen Batista dos Santos ${ }^{2}$

\section{RESUMO}

O presente trabalho tem por objetivo levantar reflexões críticas acerca da aplicação da justiça restaurativa em crimes de violência doméstica contra as mulheres, importando-nos questionar os riscos e desafios das principais experiências em curso no Brasil. Para tanto, foram realizadas revisão bibliográfica, privilegiando a teoria crítica da justiça restaurativa; análise documental de dados oficiais sobre a implementação e avaliação dos Programas brasileiros, e análise de resultados de estudos de casos efetuados no âmbito de três Juizados de Violência Doméstica no Estado do Rio Grande do Sul. Concluímos preliminarmente que as práticas, quando conduzidas sem observância dos valores e princípios da justiça restaurativa, apresentam riscos às partes envolvidas, pois violam direitos e garantias dos acusados e vinculam as vítimas ao resultado dos processos restaurativos, de forma a reproduzir violências estruturais e servindo para manutenção de opressões sistemáticas.

\section{PALAVRAS-CHAVE:}

Justiça restaurativa; violência doméstica; justiça para as mulheres.

\begin{abstract}
This study aims to raise critical reflections concerning restorative justice work in cases of domestic violence against women, in order to question the risks and the challenges from the main ongoing experiences in Brazil. For this purpose, the study carried out a literature review, particularly of the critical theory of restorative justice; an analysis of official data regarding the implementation and the assessment of Brazilian Programs; and also an analysis of the results
\end{abstract}

1Bolsista de Produtividade em Pesquisa nível 1D do CNPq, Mestre (1999) e Doutor (2003) em Sociologia pela UFRGS. Atualmente é professor titular da Pontifícia Universidade Católica do Rio Grande do Sul, atuando nos Programas de Pós-Graduação em Ciências Criminais e em Ciências Sociais. É líder do Grupo de Pesquisa em Políticas Públicas de Segurança e Administração da Justiça Penal (GPESC), membro do Fórum Brasileiro de Segurança Pública. É pesquisador associado e membro do Comitê Gestor do Instituto Nacional de Estudos Comparados em Administração Institucional de Conflitos (INCT-INEAC). Contato: rga_2006@hotmail.com. 2Mestra e Doutoranda em Ciências Criminais pela Pontifícia Universidade Católica do Rio Grande do Sul, com bolsa de estudo integral concedida pela Coordenação de Aperfeiçoamento de Pessoal de Nível Superior (CAPES). Coordenadora Adjunta Estadual do Instituto Brasileiro de Ciências Criminais (IBCCRIM) no Rio Grande do Sul. Integrante do Grupo de Pesquisa em Políticas Públicas de Segurança e Administração da Justiça Penal (GPESC/PUCRS). Fundadora da Escola Justiça Restaurativa Crítica. Consultora da Comissão de Justiça Restaurativa da OAB-SP. Professora. E-mail: michelle.kbs@ hotmail.com. 
presented at case studies at three Courts for Domestic Violence in Rio Grande do Sul. The preliminary conclusion is that practices that did not pursue the values and principles of restorative justice offer risks to the involved parties, as they violate the rights and guarantees of the defendants, and also bind the victims to the result of the restorative justice process. In the end, such practices reproduce structural violence and contribute to the maintenance of systematic oppression.

\section{KEYWORDS:}

Restorative Justice; domestic violence; justice for women.

\section{INTRODUÇÃO}

$\mathrm{Na}$ constituição do paradigma punitivo como núcleo identitário do sistema de justiça criminal, a expropriação do conflito, o controle do "criminoso" e a neutralização da vítima se tornaram elementos centrais que configuram novos problemas de (re)vitimização. Atuando de forma altamente violenta e genocida, sua relação com o sofrimento administrado pelo Estado é inegável: produz-se tanto na corporalidade vulnerável da vítima quanto na do acusado/réu/condenado e dos familiares afetados.

A certeza da pena como dor acaba se tornando tão insuportável como a violência do crime, onde ambas se anulam na objetividade dos fatos, sendo esse o único critério de justiça. É nesse processo de perda de credibilidade do paradigma punitivo, frente aos obstáculos enfrentados pelas questões subjetivas do real, antes não observadas, que o sistema penal passa a correr o risco de uma “crise sacrificial” (GARAPON; GROS; PECH, 2001, p. 267).

Por ser uma construção histórica, o sistema de justiça criminal necessitou ser questionado através de outros padrões de pensamento que buscam desaprender as premissas pré-decisionais das teorias modernas da pena. Isso por meio de extenso exercício de crítica à racionalidade penal moderna e ao seu paradigma norteador, como possibilidade real de transformar esse sistema de pensamento em uma nova teoria de intervenção na questão criminal (ou outro sistema de ideias) (PIRES, 2017). 
Nesse universo de possibilidades, a justiça restaurativa surge como um modelo radicalmente diferente de resolução de conflitos (ACHUTTI, 2016), inaugurando uma nova forma de pensar o crime e a pena, e realizando um giro histórico-científico, até mesmo no núcleo do fazer criminológico crítico, no que tange ao deslocamento da vítima do lugar subalterno de interesse da justiça criminal, especialmente do processo penal.

Sendo de suma importância apontar delineamentos conceituais para a compreensão de suas práticas, atualmente, podemos considerar que justiça restaurativa é "um processo pelo qual as partes envolvidas em uma específica ofensa resolvem, coletivamente, como lidar com as consequências da ofensa e as suas implicações para o futuro" (MARSHALL, 1996, p. 37).

Tal modelo de justiça é orientado por princípios e valores como a imparcialidade do facilitador/mediador, a confidencialidade, a voluntariedade das partes, a presunção de inocência, o empoderamento, a obediência aos limites máximos estabelecidos legalmente como sanções, a escuta respeitosa, a preocupação igualitária com todos os participantes, entre outros.

Os objetos da justiça restaurativa seriam, então, as consequências do crime e as relações sociais afetadas pela conduta, tendo por objetivo elaborar respostas que transformem as relações entre vítima, ofensor/a, comunidade e sistema de justiça. Porém, por ser um conceito aberto e fluído, suas concepções podem ser diversas, objetivando desde o encontro entre as partes, para decidirem sobre a melhor solução a ser dada para o conflito, até a reparação do dano e a transformação individual dos participantes, no que tange a forma como compreendem a si e se relacionam com os outros.

No Brasil, a justiça restaurativa surge nas primeiras décadas do século 21 e é oficialmente traduzida ${ }^{3}$ pelo poder Judiciário a partir do ano de 2005 , dando origem a uma justiça restaurativa judicial, cuja trajetória é marcada por dois momentos: (i) a implantação, tendo por marco a parceria firmada entre o Ministério da Justiça e o Programa das Nações Unidas para o Desenvolvimento (PNUD), que resultou na implementação da justiça restaurativa

\footnotetext{
${ }^{3}$ Aqui nos apropriamos do conceito de "tradução" utilizado pela primeira vez no Brasil pela Professora Vera Regina Pereira de Andrade, onde se compreende tal termo como a implicação de um processo de importação cultural na configuração de racionalidades, programas e tecnologias, por diferentes "experts" locais que operam, com essas ferramentas importadas, transformando os discursos e as práticas existentes de seus próprios contextos nacionais (SOZZO, 2001, p. 358).
} 
através de três projetos-piloto ${ }^{4}$ em 2005, e (ii) a institucionalização-expansão que tem por marco a Resolução n. 125/2010, seguida da Resolução n. 225/2016, ambas do Conselho Nacional de Justiça e impulsionadoras do uso desses programas.

Em contínuo desenvolvimento e expansão, os programas brasileiros de justiça restaurativa contam com o protagonismo do Poder Judiciário e com ideal de democratização da justiça de cima para baixo. As atividades são hegemonicamente conduzidas pela prática dos círculos de construção de paz, sem uma base teórica sólida e crítica, além da formação dos facilitadores basearem-se em profissionalização voluntária.

Há ainda uma forte influência etnocêntrica, sobretudo euroamericana, em uma dinâmica de construção do modelo de justiça mediante uma contínua recriação. Contudo, no Brasil, os limites são inúmeros, o que resulta em uma justiça restaurativa que serve de complemento ao sistema de justiça criminal tradicional, legitimando suas funções que são profundamente diversas dos princípios e valores da justiça restaurativa.

Diante disso, neste trabalho nos propomos a refletir sobre o funcionamento de programas de justiça restaurativa em um contexto específico: os Juizados de Violência Doméstica contra a Mulher, sendo nosso objeto de pesquisa as práticas restaurativas desenvolvidas nesta competência.

Movidos pela compreensão de que estes conflitos são atravessados por relações de subjetividades e poder, marcados por dinâmicas culturais, sociais, econômicas e políticas, buscou-se revelar possíveis riscos e eminentes desafios para a construção de um modelo de justiça restaurativa que concretize o paradigma emergente triangular (princípios-valorespráticas).

Para isto, expusemos resultados preliminares de pesquisa empírica desenvolvida, para, ao final, problematizar os limites da aplicação de práticas experimentais de justiça restaurativa no âmbito dos conflitos domésticos marcados por violência contra as mulheres. Assim, da prática à teoria, utilizando-se de revisão bibliográfica e análise de documentos oficiais,

\footnotetext{
${ }^{4}$ Os Projetos-piloto tiveram início em Porto Alegre e São Caetano do Sul, voltados para as condutas qualificadas como atos infracionais, e em Brasília, voltado para aquelas qualificadas como infrações de menor potencial ofensivo.
} 
desdobrou-se alguns horizontes frente a um modelo de justiça que vem se consolidando sem romper com a racionalidade do sistema de justiça criminal tradicional.

\section{EXPERIÊNCIAS RESTAURATIVAS NOS JUIZADOS DE VIOLÊNCIA DOMÉSTICA E FAMILIAR CONTRA A MULHER NO BRASIL}

Conforme o relatório "Pilotando a Justiça Restaurativa: o papel do Poder Judiciário", publicado em 2018 pelo CNJ, atualmente, existem programas de justiça restaurativa em 19 unidades da federação brasileira, alguns em fase primária de implementação e outros já consolidados, que podem estar vinculados à infância e a juventude, ou aos NUPEMECs e aos NUPECONs $^{5}$. Quanto às competências, há programas na seara da infância e da juventude, nos Juizados Especiais Criminais, nos Juizados de Violência (ou Paz) doméstica, no âmbito da execução das penas e medidas alternativas e socioeducativas, e nos Juizados do Torcedor. Isso sem mencionar a inserção das práticas na Guarda Municipal, nas escolas e na rede de serviços públicos (CNJ, 2018a, pp. 39-46).

Sendo nosso objetivo analisar a inserção e o desenvolvimento das práticas restaurativas no âmbito da resolução de crimes de violência doméstica contra as mulheres, buscamos compreender o funcionamento de 03 (três) dos 06 (seis) programas de justiça restaurativa que estão em curso no País, especificamente, na competência dos Juizados que recepcionam estes conflitos. Os seis programas estão distribuídos na Região Norte e na Região Sul, cada um funcionando de acordo com a autonomia do/a Magistrado/a que detém a coordenação do respectivo Juizado, sendo práticas que foram inseridas em plena vigência da Lei $\mathrm{n}^{\circ}$ 11.340/2006, mais conhecida como Lei Maria da Penha.

\footnotetext{
${ }^{5}$ Ambos são Núcleos Permanentes de Métodos Consensuais de Solução de Conflito, possuindo atribuições elencadas na Resolução no 125/10, do Conselho Nacional de Justiça, bem como no Provimento ${ }^{\circ}$ 2.348/16, do Conselho Superior da Magistratura, sendo suas principais atividades: instalação e monitoramento de Centros Judiciários de Solução de Conflitos e Cidadania (CEJUSC); atualização permanente de servidores, conciliadores e mediadores nos métodos adequados de solução de conflitos; criação e manutenção de cadastro de mediadores e conciliadores; desenvolvimento de política judiciária de tratamento adequado dos conflitos de interesses, planejamento, implementação, manutenção e aperfeiçoamento de ações voltadas ao cumprimento da política pública e suas metas.
} 
Nossa preocupação reside no formato de justiça restaurativa que pode se consolidar dentro do sistema de justiça criminal, no que tange aos referidos conflitos violentos. Isso porque a Lei $n^{\circ} 11.340 / 2006$, mesmo não proibindo o uso dessas práticas, tem regido outras práticas no âmbito dos processos penais que são antagônicas ao modelo restaurativista, pois são por vezes reduzidas a políticas criminais de orientação prioritariamente retributiva (CNJ, 2018, pp. 25-26). Assim, apesar de estudos demonstrarem que a proposta da Lei Maria da Penha não se consolidou como um meio efetivo de solução de conflitos domésticos para todas as vítimas (CELMER; TAVARES; SOUZA; CASTILLO, 2011; MELLO, 2015; MEDEIROS, 2015), a questão é que tal Lei também oferece inúmeros limites que dificultam a solidificação de outro paradigma de justiça para as mulheres.

Entre esses limites está o afastamento das medidas despenalizadoras, consequência do afastamento da Lei 9.099/95, impossibilitando também o momento de conciliação, de maneira que a intervenção penal, amarrada à lógica retributiva-punitiva, não tem deixado alternativas para administração desses conflitos. Contudo, a justiça restaurativa conseguiu adentrar aos Juizados, e práticas estão sendo desenvolvidas e apresentadas como outra possibilidade do agir em justiça para vítimas de violência.

Assim, com a crise do sistema de justiça criminal e os resultados insatisfatórios da Lei $\mathrm{n}^{\circ}$ 11.340/2016, e diante do estado da arte da justiça restaurativa no País, surgiu a indagação: qual modelo de justiça restaurativa se oferece nos Juizados de Violência Doméstica e Familiar contra a Mulher no Brasil?

Buscando compreender essa dinâmica, fora realizada uma pesquisa ${ }^{6}$ em três juizados no Estado do Rio Grande do $\mathrm{Sul}^{7}$ considerados unidades jurisdicionais de referência ${ }^{8}$, nos anos de 2018 e 2019. Os Projetos ali desenvolvidos são vinculados ao Programa "Justiça para o Século 21”, que é articulado pela Associação dos Juízes do Rio Grande do Sul e tem assumido como

\footnotetext{
${ }^{6}$ Tal pesquisa foi desenvolvida durante o curso de Mestrado em Ciências Criminais (PUCRS) da Pesquisadora Michelle Karen Batista dos Santos, sob orientação do Professor Rodrigo Ghiringhelli de Azevedo, tendo sido concluída e apresentada para a comunidade acadêmica em março de 2020.

${ }^{7}$ As três únicas unidades de referência do país estão localizadas no Estado do Rio Grande do Sul e são vinculadas ao Programa Justiça Restaurativa para o Século 21 do TJRS. Estas não serão identificadas aqui, pois assumimos o compromisso ético, junto às coordenadoras destes Juizados, de manter anônimo os Programas e as interlocutoras, seguindo as normas da Comissão Nacional de Ética em Pesquisa (CONEP).

${ }^{8}$ Projetos que já ultrapassaram a fase inicial de implantação.
} 
objetivo divulgar e aplicar as práticas da justiça restaurativa na resolução de conflitos, atuando de forma complementar ao sistema tradicional de justiça criminal (BRANCHER, 2008).

Através dos dados colhidos na referida pesquisa, foram desenvolvidos estudos de casos que se basearam nas seguintes atividades: participação em cursos de formação de facilitadores; acompanhamento de audiências; verificação de Expedientes e Processos Criminais; participação em Grupos de fortalecimento de mulheres vítimas; acompanhamento de círculos conflitivos de justiça restaurativa, com a presença da vítima e do ofensor; acompanhamento do Grupo reflexivo de homens, e entrevistas semiestruturadas com Magistradas e facilitadoras das referidas práticas.

O que faremos agora é apresentar os principais resultados da pesquisa de campo, ressaltando-se que as práticas aqui observadas devem ser consideradas como uma amostra local do que vem sendo aplicado no Brasil, tendo em vista que estão vinculadas à Programas específicos e são desenvolvidas a partir da autonomia de coordenação de cada Magistrada responsável pelo respectivo Juizado.

\subsection{Explorando as práticas restaurativas}

“Juizado A" - O primeiro Juizado a ser apresentado, objetiva, com a justiça restaurativa, qualificar as facilitadoras ${ }^{9}$ em gênero para contornar riscos e prevenir novos crimes de violência doméstica contra as mulheres. Sua atenção é voltada para questões de desigualdade e vulnerabilidade, de forma que o projeto sirva para uma mudança cultural mais efetiva no âmbito das relações de gênero marcadas por opressões e violências.

Neste Juizado não há Equipe Multidisciplinar, de forma que a atuação no projeto se dá de forma voluntária por pessoas que estão fazendo estágio nos cursos de formação em justiça restaurativa, ou por servidores que já fizeram o curso e atuam nessas atividades em paralelo com suas outras atribuições.

\footnotetext{
${ }^{9}$ Facilitadores/as são pessoas devidamente capacitadas e formadas para conduzir práticas restaurativas, sendo figuras essenciais para o desenvolvimento dos procedimentos. Aqui iremos nos referir a estas profissionais no pronome feminino, tendo em vista que a pesquisa revelou apenas mulheres atuando nestas práticas no contexto dos Juizados investigados.
} 
A única prática desenvolvida é o círculo de construção de paz, que pode ser conflitivo, para resolução de conflitos específicos, ou não conflitivo, para promover o diálogo em algum grupo. Esta prática foi disseminada no Brasil por Kay Pranis, instrutora norte-americana ${ }^{10}$, e tem por característica a reunião de pessoas em formato de círculo, objetivando um momento de fala e escuta sobre emoções e realidades difíceis. Ali, a facilitadora, pessoa com nível superior sem exigência de curso, devidamente formada no curso ofertado pelo Tribunal do Rio Grande do Sul em parceria com a Escola Superior de Magistratura (AJURIS), conduz a atividade a partir do processo circular ${ }^{11}$ que melhor se adeque a demanda do grupo.

A prática segue o seguinte roteiro: (1) todos/as os/as participantes sentam em círculo; (2) a facilitadora propõe um momento de meditação para os/as participantes se desconectarem de outros estímulos; (3) a facilitadora dá início a uma cerimônia de abertura para marcar o círculo como um espaço sagrado, possibilitando que os/as participantes se sintam completamente presentes no espaço e reconheçam a interconectividade com os/as outros/as; (4) a facilitadora apresenta a peça de centro, um ponto de referência que dá o suporte para falar e escutar com atenção e segurança. Esse elemento fica no centro do círculo, podendo ser usados tapetes, livros, velas, entre outros objetos, que necessariamente se comuniquem com a proposta do processo; (5) a facilitadora apresenta o objeto da palavra para regular o diálogo com os/as participantes/as. Esse objeto é passado de pessoa para pessoa em volta do círculo, de forma que somente a pessoa que estiver segurando o objeto da palavra pode falar, podendo ser qualquer objeto; (6) a facilitadora propõe que os/as participantes nomeiem os valores que eles querem para aquele momento; (7) a facilitadora propõe que os/as participantes definam diretrizes ou padrões de comunidade para o momento, servindo para estabelecer como será a condução do diálogo e comportamentos que irão tornar o espaço seguro para que falem suas verdades; (8) a facilitadora faz perguntas norteadoras, a partir do tema pré-definido, que sirvam para estimular o diálogo no início de cada rodada, encorajando a reflexão. Essas perguntas devem ser elaboradas cuidadosamente para explorar questões ou preocupações e para gerar conteúdo para avançar; (9) se no círculo estiverem tomando decisões, são feitos acordos que devem ser implementados por todos/as os/as participantes; (10) por último, a facilitadora realiza uma

\footnotetext{
${ }^{10}$ A respeito da metodologia que consagrou a hegemonia da cultura de paz no Brasil, e sobre a trajetória de Kay Pranis, confira a pesquisa de Raffaella Pallamolla (2017) sobre a construção da justiça restaurativa no Brasil.

${ }^{11}$ Os círculos podem ser usados em diversas situações e sua nomenclatura varia de acordo com a finalidade da prática no caso concreto - resolução de um conflito, construção de conexão com a comunidade, aprendizagem emocional e social, conversas difíceis, fortalecimento de equipe, envolvimento familiar, apoio intensivo, etc. (PRANIS; WATSON, 2011). Assim, podem se chamar "círculos de sentença", "círculos de celebração", "círculos de paz", entre outros, com os mais diversos propósitos (PALLAMOLLA, 2017).
} 
cerimônia de encerramento para reconhecer os esforços do círculo, reafirmando a interconexão dos presentes e os preparando para retornarem aos espaços comuns de suas vidas (PRANIS; WATSON, 2011).

Essa metodologia é aplicada nos Círculos de Fortalecimento de Mulheres Vítimas, estas que são convidadas na audiência de acolhimento. Essa audiência ocorre em até 20 dias após a comunicação do fato e pedido da medida protetiva, tendo por finalidade a compreensão da situação por parte do juízo e o encaminhamento das partes para os projetos existentes no âmbito do Judiciário e na rede de assistência. De acordo com o caso, nessa audiência a medida protetiva é mantida ou revogada, e a vítima é consultada sobre o desejo de dar prosseguimento à investigação criminal e ao futuro processo penal. Como é um momento de escuta da vítima, estando a mesma em situação de vulnerabilidade emocional ou sendo de seu interesse, a Magistrada a convida para participar dos círculos de fortalecimento. As datas são marcadas de acordo com a disponibilidade das mulheres e adotam, em todos os encontros, a metodologia circular, sempre com a presença de uma facilitadora.

Esse espaço está previsto na ${ }^{\circ}$ 11.340/2006 como medida de assistência à mulher vítima de violência, sendo que desde julho de 2015 foi escolhida a metodologia dos círculos para conduzir os encontros, momento em que o Juizado passou a desenvolver o Projeto de Justiça Restaurativa. Os círculos aplicados ali podem ser denominados de "Círculos de Apoio", pois seu propósito é prover apoio emocional às mulheres (PALLAMOLLA, 2017, p. 242), e servir de espaço que organiza pertencimento, conexão, empoderamento e compreensão entre as participantes.

Uma das práticas compreendida como mais relevantes para a pesquisa se trata dos círculos de construção de paz conflitivos, um procedimento ofertado pelo Juizado para promover o encontro entre as pessoas envolvidas em uma situação de violência. Esta prática pode ocorrer em qualquer momento do processo, para qualquer situação, independente do relacionamento mantido e do crime. O convite para participação pode ser feito em audiência, no balcão da secretaria do Juizado ou pelo interesse das pessoas, tendo em vista que são disponibilizadas cartilhas sobre a dinâmica e existem vários cartazes colados na porta do Juizado, também sobre o projeto.

Encaminhado um círculo conflitivo, primeiramente é marcado um pré-círculo, onde é conversado com as partes separadamente, a fim de que as facilitadoras compreendam as 
demandas individuais e possam escolher o melhor tema para condução do roteiro. Nesse momento também é informado que as partes podem convidar outras pessoas de confiança, que foram afetadas pelo conflito ou que possam ajudar na solução do mesmo. Ainda, as facilitadoras explicam os termos do processo restaurativo, entregando documentos que devem ser assinados por todos/as os/as participantes, são eles: termo de voluntariedade e termo de concessão de divulgação dos resultados nos Núcleos Internos de Avaliação, com possibilidade de filmagem e gravação de áudios.

Realizado o pré-círculo, é marcado o círculo, onde as partes se encontram para vivenciar o processo circular, sendo o auge deste momento a construção dos acordos para uma convivência pacífica. Estabelecido os acordos, passa-se por um momento de experiência, para que as pessoas possam colocar em prática aquilo que consensualmente estabeleceram. Após esse período, que é determinado a partir da demanda dos participantes, é marcado o pós-círculo, onde se encontram com as facilitadoras para a verificação do cumprimento dos acordos. Sendo considerado cumprido, dá-se por finalizado o processo circular, considerando ter havido sucesso na prática restaurativa. Não sendo cumprido, encerra o processo sem resultado satisfatório. A coordenação do projeto compreende que a aplicação dessa prática restaurativa não é para reatar laços, mas para pacificar relações e garantir uma restauração emocional.

Tal procedimento é sigiloso e seu conteúdo não vai para o processo criminal, de forma que não tem reflexo no mesmo. Contudo, tem-se verificado que círculos conflitivos que resultam em cumprimento do acordo impactam ações privadas ou ações penais públicas condicionadas à representação da vítima, pois após passar pelo processo, as vítimas decidem não seguir com a ação penal, entendendo que seu conflito já foi solucionado de forma satisfatória. Contudo, são poucos os casos que chegam a este procedimento, apenas 10 (dez) a cada 2.000 (dois mil) processos.

Todos os espaços anteriormente mencionados desenvolvem práticas que são vinculadas ao Centro Judiciário de Solução de Conflitos e Cidadania (CEJUSC), sendo realizados em sala própria desse Centro. Contudo, há outro espaço que é vinculado à Central Integrada de Alternativas Penais (CIAP), viabilizado através de um convênio firmado entre o Poder Judiciário e a Superintendência de Serviços Penitenciários (SUSEPE). Trata-se da Central que acompanha o cumprimento das penas restritivas de direito dos apenados que têm pena inferior a quatro anos e preenchem uma série de requisitos, como não ser reincidente e nem ter cometido crime de grave ameaça. O objetivo do convênio é ressocializar e evitar superlotação das prisões, 
e uma das penas alternativas que foram acompanhadas nessa Central, de julho a setembro de 2019, foi a participação em círculos de construção de paz.

Esse espaço também se chamou Grupo Reflexivo e para ele foram encaminhados homens que cumpriam pena restritiva de direito nas diversas competências, inclusive do Juizado de Violência Doméstica. As práticas eram de círculos de construção de paz não conflitivos e ocorriam no respectivo foro, onde apenados deveriam comparecer obrigatoriamente e assinar o controle de presença, a fim de que fosse monitorado o cumprimento da pena. Segundo informações da Magistrada, o Juizado, juntamente com o CIAP, pretendia construir um projeto piloto para solicitar a inclusão desse convênio no Programa “Justiça para o Século 21", contudo, a facilitadora cedida para condução do projeto foi transferida, inviabilizando a proposta.

Outra questão relevante é que todas as práticas vinculadas ao CEJUSC são objeto de supervisão. Há reunião mensal para reforçar os princípios da justiça restaurativa, de acordo com a Resolução $n^{\circ}$ 225/2016 do CNJ, sendo ressaltada a teoria do Professor Howard Zehr (concepção da reparação) e a metodologia da instrutora Kay Pranis (concepção da transformação). Essas reuniões são chamadas de Grupos de Trabalho e a equipe tem desenvolvido projetos que estão sendo consolidados como Política de Estado e de Município. Apesar de afirmarem que compreendem que a justiça restaurativa deve partir da comunidade, acreditam que, pela cultura punitiva ser muito presente, o Judiciário deve se colocar como precursor dessas práticas. Por ora, o GT tem como meta a implementação de Centros Comunitários de Justiça Restaurativa e dos projetos de prevenção e pacificação nas escolas. A Magistrada afirma que "o Poder Judiciário tem o potencial de ser agente de transformação social e cultural".

“Juizado B" - Nesse Juizado, o projeto de justiça restaurativa tem por base a concepção de que o sistema de justiça criminal tradicional não é suficiente para resolver conflitos que são marcados por violência doméstica e familiar contra as mulheres. Assim, se desenvolve sobre a premissa de que são necessárias outras práticas que ofereçam apoio, acolhimento, empoderamento e satisfação às mulheres vítimas, bem como práticas que proporcionem reflexão e transformação aos homens agressores.

A única prática desenvolvida, no âmbito desse Juizado, também são os círculos de construção de paz, conflitivos e não conflitivos. Por não contarem com Equipe Multidisciplinar, 
quem conduz as práticas de justiça restaurativa são voluntárias, servidoras do TJRS ou estagiárias do curso de formação.

Os círculos não conflitivos são realizados no Grupo Reflexivo de Homens e no Grupo de Apoio a Mulheres, seguindo o roteiro já exposto na descrição do Juizado A. No caso do encaminhamento dos homens, este se dá no deferimento de concessão de medidas protetivas pretendidas pela mulher vítima, onde o juízo, entre as demais proibições, determina a participação no grupo. Nesse espaço, os encontros são bem definidos: ocorrem uma vez por semana, sendo que nos três primeiros encontros são palestras acerca das temáticas que envolvem violência doméstica contra a mulher e, no quarto e último encontro, é realizado o processo circular.

Já para o Grupo de Mulheres, as vítimas são encaminhadas nos mesmos moldes do Juizado A. Aqui os encontros ocorrem vez por mês e em todos é utilizada a prática do círculo, contudo, nem sempre seguem estritamente o roteiro. Os encontros duram cerca de 01 (uma) hora e não há a necessidade de estar vinculada à um processo criminal para participar. Mesmo assim, há baixa adesão, de forma que geralmente o grupo conta com a presença de 05 a 10 mulheres por encontro.

A dinâmica também é diferente no que tange os círculos conflitivos. Estes são realizados após a publicação da sentença, devendo estar presentes alguns requisitos: deve se tratar de crime de lesão corporal, sendo a ação penal pública incondicionada à representação da vítima; o réu deve confessar o crime no curso do processo e demonstrar arrependimento; o réu não pode ser reincidente; a Magistrada deve avaliar se as partes estão em equilíbrio de poder, para não gerar processos de revitimização, sendo esta avaliação de risco feita sem critérios objetivos; as partes devem estar mantendo um relacionamento afetivo entre si e a condenação à pena privativa de liberdade não pode ser superior a 02 (dois) anos.

Estando presentes os requisitos, o Juízo intima a vítima e o agressor para comparecer no dia da publicação da sentença condenatória. Após a leitura do relatório e do dispositivo da sentença, a Magistrada informa às partes sobre a possibilidade de aplicação do instituto da suspensão condicional da pena, onde, durante a suspensão, o condenado ficará sujeito à observação e ao cumprimento das condições estabelecidas pela juíza, de acordo com os artigos 77 e 78 do Código Penal. Para tanto, investido no poder de especificar as condições para aplicação do sursis, a Magistrada apresenta o projeto de justiça restaurativa, garantindo que se 
as partes participarem do procedimento, ao final, firmando e cumprindo os acordos, será extinta a pena privativa de liberdade. Ao contrário, caso "escolham" participar e não consigam firmar ou cumprir os acordos estabelecidos, a sentença condenatória será encaminhada para a execução criminal.

No caso de aceite, o que ocorre na maioria dos casos, as partes são encaminhadas para o círculo conflitivo, onde os procedimentos são os mesmos apresentados na descrição do “Juizado A". Nesses círculos, a relação afetiva é o objeto da prática, tendo por finalidades prevenir novas violências, estabelecer acordos para manutenção de uma relação afetiva saudável e transformar os comportamentos que foram impulsionadores do conflito.

A aplicação de círculos conflitivos nesta unidade iniciou em setembro de 2017 e até o momento foram vinte casos enviados. Desse total, quatro casais desistiram antes de completar o processo restaurativo; os que completaram, por sua vez, resultaram na extinção da pena imposta ao agressor. De acordo com o monitoramento anual do Juizado, de todos os casos que obtiveram êxito, os participantes não voltaram a se envolver em novos episódios de violência doméstica.

Isto porque, esses acordos são anexados no processo e geram reflexos na decisão de extinção da pena ou revogação da suspensão, e, no caso de extinção, faz-se um monitoramento regular para verificar se aqueles homens voltaram a delinquir, de forma que a não reincidência é o que garante o sucesso do projeto.

“Juizado C" - A coordenação desse Juizado afirma que não fazem justiça restaurativa, apenas aplicam práticas restaurativas em alguns espaços, sem obrigatoriedade. A única prática desenvolvida ali são os círculos de construção de paz, que são facilitados por servidoras do Juizado, que também não conta com uma Equipe Multidisciplinar para trabalhos mais específicos.

Contudo, esse Juizado desenvolve desde 2014 um projeto de combate à violência contra a mulher, visando a proteção das vítimas e a reeducação dos homens envolvidos em casos de agressão. Estando bem solidificado, o projeto conta com uma equipe estruturada e oferece formação em gênero para outras Comarcas. Assim, as práticas restaurativas foram inseridas dentro deste projeto, sendo oferecidos círculos não conflitivos nos Grupos Reflexivos de 
Gênero para homens e nos Grupos de Mulheres, seguindo o mesmo formato de encaminhamento dos outros Juizados.

O Grupo Reflexivo de Gênero existe desde 2011 e, ao todo, são doze encontros, uma vez por semana, sendo que o primeiro é uma entrevista individual. Nesses encontros são desenvolvidas várias atividades, inclusive o círculo não conflitivo, com o objetivo de educar e reabilitar os agressores. A prática restaurativa não é uma regra, inclusive, mesmo quando ocorrem, nem sempre se segue o roteiro do processo circular.

Já o Grupo de Mulheres é a peça central do projeto, pois tem se consolidado como um espaço potente de apoio, fortalecimento e emancipação. Os encontros ocorrem uma vez por semana e chegam a contar com mais de 20 mulheres, não necessariamente vinculadas a algum processo criminal. Nesse grupo também se aplica a prática do círculo não conflitivo, contudo, com o roteiro bem flexibilizado. Muitas vezes sequer se usa a peça de centro, o objeto da palavra e as cerimônias de abertura e fechamento. Apenas se utiliza da metodologia para propor o diálogo, seguida da fala e da escuta, do processo de reconhecimento e pertencimento. Entretanto, é bem rara a utilização dessa metodologia, na maioria das vezes são oferecidas palestras sobre os mais variados temas, oficinas de capacitação profissional, arte-terapia, leitura coletiva, entre outras.

Nota-se que esse é um espaço fundamental para as mulheres, onde muitas afirmam que conseguiram reconhecer a violência sofrida e se fortalecer para sair dos relacionamentos abusivos. Algumas já participam a mais de dois anos, e dizem ser o espaço mais seguro e o que melhor foi ofertado a elas desde a primeira vez que recorreram ao sistema penal. Contudo, mesmo com as mulheres vítimas utilizando o grupo para expor suas insatisfações com os procedimentos da justiça criminal tradicional, pôde se perceber que há um reforço da ideia de que a responsabilização do agressor deve se dar mediante a punição determinada pelo Juízo.

Assim, apesar de adotar práticas restaurativas, o projeto desenvolvido neste Juizado está sedimentando na importância da Lei Maria da Penha, considerando um avanço o impedimento das penas alternativas e o endurecimento penal para crimes dessa espécie. Dessa forma, estimula-se a busca pelos serviços do sistema tradicional e o entendimento de que as demais práticas são apenas o oferecimento de um serviço de assistência e apoio. 
Entretanto, dentro deste programa de justiça restaurativa, são os círculos conflitivos que assumem papel de protagonismo. Tecnicamente essa é a prática mais consistente e fiel à proposta do paradigma restaurativo, envolvendo vítimas, ofensores e suas comunidades de apoio na resolução do conflito violento vivenciado. Adota-se essa metodologia, portanto, para que os/as envolvidos/as consigam se conscientizar dos diversos fatores motivacionais e percebam o dano como uma ação concreta que fere alguém, necessitando ser reparado.

Acerca do encaminhamento para esse procedimento, o mesmo pode ser feito pela magistrada ou pela coordenadora do programa e os casos passam por análise de risco, onde se verifica a possibilidade de facilitar um espaço onde vítima e ofensor se encontrem para tomar decisões consensuais. Mas essa também não é uma prática utilizada com frequência no Juizado, de forma que a Magistrada realiza entre 200 a 400 audiências por mês e apenas 10 (dez) casos são encaminhados por ano ao Programa de justiça restaurativa.

Ainda, esta prática nunca terá impacto em ações penais públicas incondicionadas à representação da vítima, podendo gerar efeito somente quando se tratar de ações que requeiram a representação, de maneira que a participação pode alterar o desejo da vítima no que se refere ao processamento criminal da conduta do seu agressor, por já ter obtido resultado na justiça restaurativa.

O conteúdo que vai para a Magistrada tomar conhecimento, à vista disso, é apenas um relatório preenchido pelas facilitadoras, contendo nome das pessoas, número do processo e resultado do procedimento. Em geral, as falas que surgem no decorrer dos círculos não podem ser divulgadas, atendendo a diretriz fundamental que é a confidencialidade. O que for mencionado neste relatório também não pode servir como prova no processo, ficando claro para eles/as desde o início.

Por fim, como evidenciado, a realização de círculos conflitivos é ínfima frente à quantidade de casos que chegam anualmente ao Juizado, demonstrando a falta de protagonismo da justiça restaurativa no âmbito judicial, mesmo em espaços onde os Programas já passaram da fase inicial de implantação. 


\section{RISCOS QUE REVELAM LIMITES E CONTORNAM DESAFIOS PARA A CONSTRUÇÃO DE UMA JUSTIÇA RESTAURATIVA PARA AS MULHERES}

$\mathrm{Na}$ competência dos Juizados de Violência Doméstica observados, foi possível compreender que na maioria dos espaços onde as práticas são utilizadas, não se trata de aplicação concreta da justiça restaurativa, mas do uso de uma metodologia específica de baixa incidência. O que se percebe é que os projetos desenvolvidos tem uma forte ligação com uma "militância" das Magistradas e facilitadoras na área, de forma que os projetos só evoluem de acordo com o interesse dessas sujeitas.

Nas considerações iniciais, falamos sobre as concepções de justiça restaurativa, que apesar de diversas não são antagônicas, e com a pesquisa foi possível perceber que as práticas restaurativas desenvolvidas nesses Juizados são completamente vinculadas à concepção da transformação, inclusive da transformação de quem protagoniza os projetos. De fato, nesses espaços, independente da prática utilizada (círculos conflitivos ou não conflitivos), acredita-se que, a partir das intensas experiências pessoais vivenciadas nos círculos, é possível obter a transformação na forma como cada um percebe e encara seu modo de vida (ACHUTTI, 2016, p. 66), sendo possível impactar toda uma comunidade.

Contudo, a adoção exclusiva dos círculos de construção de paz e, consequentemente, o alinhamento à concepção da transformação, fez com que se perdesse o potencial da justiça restaurativa crítica. Isto porque se deixou de dar ênfase à liberdade de manifestação dos envolvidos para resolução do conflito e tirou-se o foco da reparação do dano causado. Além disso, o protagonismo das Magistradas e das facilitadoras, na organização e aplicação da referida metodologia, confrontou-se diretamente com um dos pontos mais importantes desse modelo de justiça, que é a atribuição de papéis de protagonistas aos/às envolvidos/as e a imprevisibilidade da dinâmica e dos resultados de um evento restaurativo (ACHUTTI, 2016, p. $67)$.

O que vem ocorrendo não é uma complementação das instituições legais para melhorar o resultado do processo de justiça (OXHORN; SLAKMON, 2005, pp. 198 - 120), ao contrário, se trata da implantação de uma única metodologia proporcionalmente pouco aplicada, baseada na ideia de pacificação de conflitos e instituída em conjunto com a investigação, o processo 
criminal e/ou a execução penal. Um ideal de "cultura da harmonia" que facilmente se transforma em um elemento de coerção (NADER, 1994).

O discurso da pacificação somado a concepção da transformação começa a delinear uma das principais funções da justiça restaurativa judicial brasileira: ressuscitar o ideal da ressocialização no seio de um sistema de justiça criminal que é orientado pelo paradigma punitivo e repressivo. A perda do seu caráter democrático reside aqui, onde não está sendo privilegiada nem a participação da vítima, nem a da comunidade (PALLAMOLLA, 2017, p. 260). O foco não é conflito, mas a pacificação das relações que resulte na ausência do conflito. O foco não é a vítima, mas a transformação individual do agressor, que ao passar por todo procedimento criminal repressivo, também passará pelo programa de justiça restaurativa para ser corrigido.

No que diz respeito à reparação de danos, apesar de ser um princípio fundamental, este está vinculado à outra concepção de justiça restaurativa. Quando se privilegia a aplicação dos círculos não conflitivos, em grupos de apoio a mulheres e grupos reflexivos de homens, isto se torna apenas mais uma dinâmica dentro de grupos assistencialistas, de apoio e prevenção. $\mathrm{O}$ próprio roteiro a ser seguido mistifica o procedimento, não deixando espaços para se pensar justiça, acordos consensuais e solução do conflito. Até porque o conflito está sendo "solucionado" mediante o sistema tradicional e, se for o caso, o dano será "reparado" através da punição, sendo o procedimento restaurativo apenas um meio de transformação individual e, talvez, coletiva.

Nos Juizados, o encaminhamento para o Grupo Reflexivo de Homens se dá no deferimento da concessão das medidas protetivas, assim, independente de não ser prevista punição para a não participação no Grupo, e não ser regra o desenvolvimento de práticas restaurativas, o que está posto é a imposição do encaminhamento, muitas vezes aliada às inúmeras proibições que são restritivas de liberdade. Portanto, é possível aferir que não se trata de justiça restaurativa o que se desenvolve nesses grupos, apenas a aplicação de processos circulares em momentos específicos.

Já nos grupos de mulheres o convite se dá de forma acolhedora, onde é permitido a vítima exercer sua voluntariedade. Os danos causados a elas e suas necessidades são observados com atenção, contudo, em uma dinâmica de fortalecimento e não em uma perspectiva de resolução do conflito. O formato de aplicação das dinâmicas circulares acaba não impedindo 
que a mulher seja submetida às iniquidades do sistema de justiça criminal, de forma que a revitimização, a não compreensão dos procedimentos, a impossibilidade de escolha, entre outras, ainda serão um risco (CNJ, 2018; LARRAURI, 2008).

Neste cenário, a prática restaurativa não consegue romper com a mentalidade de que os profissionais são os mais aptos a decidir como as pessoas diretamente atingidas pela ação delitiva devem ser tratadas. Ao contrário da perspectiva positiva de Rosenblatt e Melo (2015, p. 104), os procedimentos não têm possibilitado as vítimas opinarem sobre o destino do seu próprio caso e, do mesmo modo, não oportunizam que os agressores assumam sua conduta violadora, a fim de enfrentar as consequências para além do sistema de justiça criminal tradicional. Desse modo, essas práticas não têm servido para reparação de danos e não assumem seu potencial de fortalecer membros da comunidade para que resolvam conflitos comunitários e sirvam de acolhimento das partes envolvidas nas situações de violência.

Um argumento relevante, sobre a possibilidade de aplicação de práticas restaurativas em conflitos domésticos marcados por violência contra a mulher, é a verificação empírica de que a maioria das vítimas não deseja a punição do seu agressor, enxergando o processo como um meio para mudar o comportamento violento (CNJ, 2018, p. 71).

Nesse sentido, a justiça restaurativa propõe, justamente, uma forma de enfrentar o problema público da violência doméstica, diversificando a forma de responder a essas demandas sociais, ampliando a rede de proteção à mulher e possibilitando uma resolução satisfatória do conflito (CORREIA, 2015, p. 96). Entretanto, as experiências dos Juizados têm demonstrado suas incapacidades de bloquear o avanço do paradigma punitivo e de sua destrutividade. Ou seja, independente da vontade da vítima, o viés punitivo e repressivo se expressa com maior amplitude, não deixando espaço para a consolidação de uma justiça estruturalmente democrática e restaurativa.

Os círculos conflitivos, que ocorrem no Juizado B, demonstram um pouco da problemática de uma "justiça restaurativa" sem regulamentação legal, que não tem meios para lidar com o legalismo característico da cultura jurídica brasileira (ACHUTTI, 2016). Pelo que se pôde observar, os conflitos de competência desse Juizado passam pelo procedimento tradicional da justiça criminal e, caso cumpram os requisitos já mencionados, podem ser encaminhados para a justiça restaurativa após a publicação da sentença condenatória. 
Tal encaminhamento é feito pela Magistrada, que cria sozinha diretrizes e regras para disciplinar o uso do programa, com aval do Ministério Público, da Defensoria Pública e, se for o caso, do/a Advogado/a particular. Contudo, apesar dos casos poderem ser encaminhados para programas restaurativos em diferentes momentos do processo penal tradicional, inclusive na fase pós-judicial (PALLAMOLLA, 2009, pp. 100-104) percebe-se que se trata de uma experimentação de resultados sem a observação dos possíveis riscos.

Foi verificado que não se aplica uma avaliação de risco formal para enfrentamento de novas violências, o que é imprescindível para compreender a situação atual da relação entre os envolvidos e aferir se há equilíbrio de diálogo entre eles. Dessa forma, a partir de requisitos informais, oferece-se a justiça restaurativa como alternativa à pena imposta, mas formalmente estabelecida dentro da suspensão condicional da pena, se operacionalizando como pena alternativa. Assim, é apresentada e compreendida como um benefício ofertado pelo Juizado, que sem um aconselhamento legal facilmente se alinha a uma indução de participação no processo restaurativo por meios desleais (ONU, 2002).

Sendo assim, se manifesta o risco das vítimas estarem sendo submetidas a participarem desses programas para auxiliar a extinção da pena dos seus companheiros, sendo possível que mantenham a relação de abuso e violência para garantir a conclusão do procedimento (PADÃO, 2019). Além disso, a não minimização das desigualdades entre as partes, pode levar à revitimização da mulher, já que há a possibilidade, no procedimento de estabelecimento de acordos, de ela não explorar suas verdadeiras percepções e vontades em prol dos desejos do agressor (GIONGO, 2009, p. 90).

Ainda, o momento de aplicação e as consequências jurídicas não dão espaço para o princípio da voluntariedade da participação das partes (ONU, 2002), pois a vítima é colocada em uma posição de responsabilização pela aplicação da pena e o agressor é induzido a optar pelo "benefício" de participação frente à pena imposta.

Eventual desistência ou descumprimento de algum dos requisitos pode ainda gerar prejuízos, como a revogação da suspensão condicional da pena e o encaminhamento à execução criminal. Consequentemente, o crime praticado pode ser apenado pelo programa de justiça restaurativa e, no caso de descumprimento de acordos vinculados ao programa, pelo sistema de justiça criminal. Verifica-se, então, que estão sendo descumpridas as regras para operacionalização dos programas, conforme o disposto na Resolução n. 2002/12 da ONU. Isso 
porque tal Resolução proíbe, expressamente, o bis in idem (art. 15), e prevê que a ausência de acordo não poderá justificar uma pena mais severa (art. 16).

Outra questão, é que um dos requisitos para encaminhamento ao programa de justiça restaurativa, no Juizado B, é o fato ser configurado como crime de lesão corporal. Contudo, o artigo 44, inciso I, do Código Penal, somado ao artigo 77, inciso III, do mesmo Código, prevê a proibição da suspensão condicional da pena quando se tratar de crime cometido com violência ou grave ameaça. Posto isso, a leitura que pode ser feita é que não se considera o crime de lesão corporal contra a mulher um ato de violência.

Além do mais, o artigo 41 da Lei no 11.340/2006 e a Súmula 588 do SJT consolidam o entendimento de que não é possível substituir a pena privativa de liberdade por restritiva de direitos nos casos de violência contra a mulher ou grave ameaça em ambiente familiar. Isso implica no desenvolvimento das práticas restaurativas, que sem a observação dos referidos dispositivos podem levar a compreensão de que se está banalizando a violência doméstica, inserindo tais condutas no rol de menor potencial ofensivo. Tal ocorrência oferece base para os argumentos que são contrários à aplicação da JR na violência doméstica, favorecendo o entendimento de que tais práticas estão descriminalização a violência doméstica masculina, produzindo retorno ao estado de problema "privado" ou particular (MORRIS, 2005, p. 447).

Tal procedimento se alinha ao slogan "Paz em Casa" e ao ideal de pacificação de conflitos, já que a prática de círculo conflitivo facilmente se confunde com terapia de casal (PADÃO, 2019), sendo ensinado como as partes devem manter uma relação mais saudável e livre de violência. De fato, não se tem solucionado o conflito, servindo apenas para legitimar a pacificação das relações de gênero, onde o foco é a não reincidência por parte do agressor, mas sem a preocupação com as demandas da vítima.

Assim, não é possível afirmar que se faz justiça restaurativa nesse Juizado, apenas se faz a experimentação de práticas que somadas ao processo penal sirvam para prevenir que o agressor pratique novos atos de violência doméstica.

Os círculos não conflitivos de construção de paz, desenvolvidos no CIAP, seguem a mesma lógica: atuam como pena alternativa e visam a não reincidência. Por se tratar apenas de práticas restaurativas destinadas de forma obrigatória à apenados, além de eliminar o princípio da voluntariedade, também perde o potencial de resolução de conflitos e de reparação dos danos 
causados às vítimas. Tal procedimento está estritamente ligado à ressocialização e a prevenção, também funções da pena, de forma que a ligação com a justiça criminal não é para provocar a redução do uso desse sistema, mas para legitimar suas "funções". A justiça restaurativa brasileira acaba se tornando um apêndice expansionista do controle penal.

Esse cenário demonstra o processo de construção da justiça restaurativa no Brasil que não é exclusivo dos Juizados de Violência Doméstica contra a Mulher. Evidencia-se um discurso oficial de pacificação social e cultura de paz, somado a uma única prática que o potencializa: círculos de construção de paz (PALLAMOLLA, 2017). Toda a dinâmica indica não só o protagonismo do Poder Judiciário, mas também a autonomia das Magistradas que ao assumir o discurso oficial e instituir a prática dominante se coloca como agente de justiça restaurativa. E por mais que os programas sigam a mesma lógica, essa autonomia garante que eles funcionem de forma totalmente diversa.

A expansão da implementação desse modelo de justiça e a experiência dos Juizados de Violência Doméstica contra a Mulher, permitem uma profunda reflexão sobre os desafios para a consolidação desses programas no Brasil. É primordial que o objetivo seja construir uma justiça restaurativa que inove positivamente o campo da administração de conflitos e não que seja apenas um instrumento de continuidade de velhas lógicas e práticas (PALLAMOLLA, 2017). Para tanto, compreende-se que, apesar da possibilidade de perda de potencialidade frente ao sistema de justiça criminal, há que se enfrentar a questão da regulamentação legal.

Regulamentar a justiça restaurativa é a forma direta de lidar com o legalismo característico da cultura jurídica brasileira (ACHUTTI, 2016), diante de um modelo que já está inserido no âmbito do Poder Judiciário. Seria o meio pelo qual se evitaria que a autonomia dos/as Magistrados/as resulte em descaracterização do conceito e das práticas, de forma a criar diretrizes e regras que disciplinem o uso de programas. A regulamentação também pode servir de estimulo para o uso das metodologias e quebrar tanto as resistências de agentes jurídicos, que muitas vezes rejeitam temas potencialmente inovadores, quanto dos/as Magistrados/as adeptos que resistem a interferências externas (PALLAMOLLA, 2017, p. 270).

A autonomia dos núcleos de justiça restaurativa é outro ponto a ser observado. É imprescindível que esses espaços sejam instituídos a partir de uma nova linguagem que subverta o paradigma punitivo. Seja no grupo de mulheres, seja no grupo de homens, ou nas possibilidades de desenvolvimento de círculos conflitivos, há que se romper com a lógica dual 
vítima-agressor, passiva-ativo. Os serviços devem ser disponibilizados como meios das pessoas se enxergarem como sujeitos das relações, não como manutenção da concepção de que mulheres são não-sujeitos que gestionam relações afetivas, e que homens são naturalmente sujeitos dominadores que exercem poder de forma unilateral.

A justiça restaurativa também não pode ser um meio para retornar o conflito doméstico para o espaço privado, ao contrário, deve possibilitar que no espaço público seja minimizada a revitimização, a estigmatização do ofensor, as políticas com viés estritamente punitivo, a indiferença por parte dos atores jurídicos e a insatisfação com os resultados.

Esses programas devem buscar a integração, inclusive em nível institucional, para que seja possível criar uma rede permanente capaz de conferir visibilidade a outras práticas de acesso à justiça. Também, há que se definir quais são os objetivos de se desenvolver práticas restaurativas nos Juizados de Violência Doméstica, para que seja possível diminuir os riscos e enfrentar os desafios.

Avaliações técnicas e qualitativas são imprescindíveis, devendo ser realizadas com o intuito de melhorar o método empregado e conceber outros métodos, incentivando que, na ausência de normatização, os princípios e valores que constituem a justiça restaurativa sejam observados em totalidade. Igualmente, devem ser privilegiados programas que contem com capacitação e formação para além das práticas restaurativas, ou seja, com profunda atenção à natureza do conflito que se destina a intervenção, sendo requisito observar as questões de gênero, sexualidade, raça, classe e demais identidades que atravessam as vidas dos sujeitos, em especial das mulheres vítimas.

Outros aspectos merecem ser expostos, em relação ao perfil e execução dos programas: (i) devem ser transparentes e compartilhar métodos, custos e resultados; (ii) os serviços disponibilizados devem fazer parte de uma rede interdisciplinar de apoio; (iii) devem valorizar a participação de facilitadores que tenham experiência e preparo adequado para lidar com esse tipo de conflito; (iv) devem estimular a participação das universidades na avaliação dos programas; (v) devem garantir uma avaliação formal de risco para evitar a revitimização da mulher; (vi) devem conceder espaço de escuta aos homens agressores, contudo, tal procedimento não pode ser obrigatório; (vii) o encontro entre as partes não pode ser oferecido como pena alternativa ou como manutenção da relação, e, por fim, (vii) a inserção da comunidade não deve ser prioritária nas práticas, ao contrário, há que se fazer um trabalho de 
integração e conscientização, a fim de que a comunidade sirva de apoio, primordialmente, fora do espaço do judiciário.

A observação dos riscos pode levar a caminhos para a superação dos desafios. Caminho que deve ser trilhado de forma responsável e baseado nos aspectos que estão sendo levantados nas pesquisas acadêmicas. Como concluiu Pallamolla (2017, p. 273), é fundamental que "o campo jurídico se desacomode, e que tanto o Poder Judiciário quanto a academia se abram ao diálogo", de maneira que seja possível consolidar uma justiça restaurativa estruturada para ser um instrumento útil de redução da atuação danosa do sistema de justiça criminal.

Outro aspecto de profunda importância, é que se reconheça que os movimentos de mulheres e vítimas são impulsionadores da justiça restaurativa desde sua origem, motivo pelo qual é também urgente reconhecer que os movimentos feministas brasileiros, vinculados à teoria e prática do feminismo negro, já vêm dialogando e trilhando há algum tempo o caminho do pensar-fazer uma justiça que contemple as mulheres.

Nesse sentido, relembra-se a organização de mulheres latino-americanas ao redor da articulação entre justiça e feminismo, resultado do "Primer Encuentro Feminista Latinoamericano y del Caribe sobre Justicia"12, ocorrido no Equador em setembro de 2019. Esse encontro que envolveu mulheres de todo o mundo, convocou as participantes a refletir sobre o sistema penal e penitenciário, dado que são os aparatos da justiça estatal com maior alcance e impacto social, porém, não produzem resultados efetivos diante do aprofundamento das violências contra as mulheres.

Desde essa percepção, se alargou a crítica feita ao sistema, indicando ser orientado por um paradigma punitivo que está atrelado à violência patriarcal gerida seletivamente entre o punitivismo e a impunidade. Para tanto, se afirmou a capacidade de diversos movimentos feministas, de todo o mundo, colocar radicalmente em questão a noção de justiça como ato único e final que parte da objetividade da autoridade estatal.

Hemos ensayado otros modos de ejercer justicias reparadoras para nosotras y los nuestros, en la desigualdad y la diversidad, siempre en plural, sin pretender una definición única y última de justicia. Lo hemos hecho sin ingenuidad, con alta

\footnotetext{
${ }^{12} \mathrm{O}$ portal que movimenta essa articulação pode ser consultado aqui: https://justiciasyfeminismos.org/se-abreninscripciones-para-el-i-encuentro-feminista-latinoamericano-y-del-caribe-sobre-justicia/.
} 
conciencia de cómo en nuestros territorios las masculinidades violentas son estimuladas por las dinámicas de acumulación de capital y por el Estado punitivo. Buscando justicia, aquí y ahora, para poner límites a las violencias estatales, paraestatales y civiles que nos oprimen; para fortalecernos, sanar y continuar. A la vez, desde nuestra diversidad, hemos planteando la necesidad de trabajar en la erradicación de la cultura de la violencia. Y hemos creado las condiciones para imaginar un sistema de justicia público que cumpla efectivamente con los derechos a la verdad, la justicia y la reparación de las mujeres, los niños, las niñas y las personas sexualmente diversas, sin expropiarnos de nuevo la capacidad de hacer justicia desde nuestras experiencias y tramas comunitarias.

Esa crítica y la puesta en común de experiencias de justicias alternativas no pueden producirse sino desde una perspectiva interseccional, es decir, atenta a las dinámicas de desposesión y violencia racista y machista que han hecho de la justicia de estado un privilegio de pocos y un dispositivo letal para aquellas señaladas como transgresoras y para las que exigen justicia reparadora. ${ }^{13}$

A justiça restaurativa entra nessa proposta como objeto de reflexão e investigação para as lideranças e integrantes de diversos movimentos organizados ou não, mas que pautam comumente a necessidade de pensar alternativas ao sistema vigente, em prol da vida das mulheres. Nesse processo também entra a possibilidade de criar condições de solidariedade, apoio e proteção para as mulheres que denunciam, garantindo um resultado reparatório que produza memória histórica e organização coletiva, permitindo também alcançar dignidade e reconhecimento no fortalecimento de vínculos entre as próprias vítimas (FULCHIRON, 2017, pp. 108).

$\mathrm{Na}$ emergência e na criticidade da justiça restaurativa, construída sobre a validade discursiva e material da comunidade de vítimas, acredita-se que é possível acessar uma abordagem do mundo da vida que traz à superfície as feridas e ferimentos da violência doméstica em suas diversas manifestações.

A possibilidade do encontro, mediante o exercício do diálogo, expõe um terreno ainda não explorado em profundidade no Brasil. Talvez sejam práticas que revelem nada mais que uma indicação de disposição para tentar mudar e assumir uma nova maneira de comunicação e relação entre os sujeitos. Mas é aí que reside o potencial do começo da transformação que precisa ser estimulada para causar um impacto duradouro na vida cotidiana (PELIKAN; HOFINGER, 2016, p. 341).

\footnotetext{
${ }^{13}$ Manifesto de convocatória. Ver: https://justiciasyfeminismos.org/se-abren-inscripciones-para-el-i-encuentrofeminista-latinoamericano-y-del-caribe-sobre-justicia/.
} 
Para tanto, a elaboração de um programa crítico de ação é medida que se impõe, conforme afirmação de Dussel quando trata sobre a imaginação transcendental ao sistema vigente: "Se o atual não permite que se viva, é preciso imaginar um mundo onde seja possível viver" (Dussel, 2007, p. 476). A esperança entra nesse cenário diante do futuro possível, alertando que é preciso construir e não se afogar no pessimismo que paralisa e enseja na desistência de disputar as alternativas que ainda oferecem possibilidades de resistência à repressão e à exclusão.

\section{CONSIDERAÇÕES FINAIS}

Se os procedimentos tradicionais do sistema penal são incapazes de assimilar a complexidade e as singularidades desse tipo de conflito violento, tendendo a reproduzir os mesmos marcos de poder que vitimizam as mulheres (ANDRADE, 2005), o que se esperou da justiça restaurativa foi a recepção e percepção do que se trata a dor da mulher vítima. Onde a potência da fala e da escuta se revelasse através do reconhecimento das condições de vida dos

sujeitos, das singularidades do conflito e da forma como esses sujeitos dão sentido às relações que chegam para ser mediadas pelo direito penal e pela institucionalização do Poder Judiciário.

Todavia, a partir do exposto acima resta perceptível que a justiça restaurativa brasileira tem muito a caminhar para conseguir alcançar as expectativas oriundas da apreensão de suas promessas. A sorte é que ela ainda está em processo de construção e implementação (PALLAMOLLA, 2017), estando disponível para disputas no que tange à sua consolidação.

A Lei 11.340/2006 não proibiu o uso de práticas restaurativas no âmbito de sua competência, contudo, apresenta inúmeros limites para o desenvolvimento e consolidação de programas restaurativos capazes de potencializar a democracia na gestão dos conflitos interpessoais. Esses limites em conjunto com a justiça restaurativa que é construída no país, garantem que, a partir da avaliação das práticas, não seja possível verificar a potencialidade desse modelo de justiça para além dos assistencialismos.

Assim, mesmo com a regulamentação legal e a autonomia dos núcleos de justiça restaurativa, é possível que ainda não se faça justiça restaurativa nos Juizados de Violência 
Doméstica contra Mulher. Os limites legais e a necessidade do Estado de ofertar respostas às mulheres vítimas dentro de um sistema repressivo e punitivo impede a percepção da singularidade de cada caso, massificando os conflitos como se todas as relações fossem estruturadas da mesma forma.

Ainda, a não participação ativa das partes impede a tomada de decisão em conjunto, resultando na predominância do sistema de justiça criminal tradicional, que ao recepcionar a justiça restaurativa a marginaliza, sufocando-a. Assim, o uso desse sistema não é reduzido, ao contrário, é expandido, na medida em que as novas funções da justiça restaurativa o complementam.

Percebe-se, então, que não é adequado fazer experimentações de programas restaurativos no âmbito da violência doméstica, pois a não observação dos princípios e valores que orientam as práticas está produzindo efeitos que mais se alinham à lógica do sistema de justiça criminal, gerando riscos às pessoas envolvidas. Contudo, a manutenção desses programas implica atenção aos desafios que precisam ser enfrentados para diminuir os riscos gerados, estando entre eles o principal: inserir no centro das propostas filosóficas e políticas de justiça o corpo e a vida das mulheres, nos marcos da diversidade e da pluralidade.

\section{REFERÊNCIAS BIBLIOGRÁFICAS}

ACHUTTI, Daniel Silva. Justiça restaurativa e abolicionismo penal: contribuições para um novo modelo de administração de conflitos no Brasil. 2.ed. São Paulo: Saraiva, 2016.

ANDRADE, Vera Regina Pereira de. A soberania patriarcal: o sistema de justiça criminal do tratamento da violência sexual contra a mulher. Revista Sequência, Florianópolis, n. 50, pp. 71-102, jul. 2005.

BRANCHER, Leoberto. Apresentação: coordenação do Projeto Justiça para o Século 21. In: BRANCHER, Leoberto e SILVA, Susiâni (Orgs.). Justiça para o século 21: Semeando Justiça e Pacificando Violências. Três anos de experiência da Justiça Restaurativa na Capital Gaúcha. Porto Alegre: Nova Prova, 2008.

CELMER, Elisa Girotti; TAVARES, Bruna; SOUZA, Marta; CASTILLO, Maurício. Sistema penal e relações de gênero: violência e conflitualidade nos juizados de violência doméstica e familiar contra a mulher na cidade do Rio Grande (RS/Brasil). In: AZEVEDO, Rodrigo Ghiringhelli de (org). Relações de gênero e sistema penal. Violências e conflitualidade nos Juizados de violência doméstica e familiar contra a mulher. Porto Alegre: EDIPUCRS, 2011, p. 93-105. 
CNJ - CONSELHO NACIONAL DE JUSTIÇA. Relatório Analítico Propositivo. Justiça pesquisa direitos e garantias fundamentais - entre as práticas retributivas e restaurativas: a Lei Maria da Penha e os avanços e desafios do Poder Judiciário. 2018. Disponível em: http://www.cnj.jus.br. Acesso em: 03 fev. de 2021.

CNJ - CONSELHO NACIONAL DE JUSTIÇA. Relatório Analítico Propositivo. Justiça pesquisa direitos e garantias fundamentais - pilotando a justiça restaurativa: o papel do poder judiciário. 2018a. Disponível em: http://www.cnj.jus.br. Acesso em: 03 fev. de 2021.

CORREIA, Thaize de Carvalho. A justiça restaurativa aplicada à violência doméstica contra a mulher. In: VALOIS, Luiz Carlos et. al. (orgs.). Justiça restaurativa. Belo Horizonte: Editora D’Plácido, 2017.

DUSSEL, Enrique. Ética da libertação na idade da globalização e da exclusão. Tradução de Ephraim Ferreira Alves, Jaime A. Clasen, Lúcia M. E. Orth. 3. ed. Petrópolis, RJ: Vozes, 2007.

FULCHIRON, Amandine. Actoras de cambio en Guatemala: poner el cuerpo y la vida de las mujeres en el centro de la justicia. In: AZKUE, Irantzu Mendia ; ORELLANA, Gloria Guzmán; LANDALUZE, Iker Zirion (eds.). Género y justicia transicional. Espanã: Universidad del País Vasco/Euskal Herriko Unibertsitatea, pp. 84-112, 2017.

GARAPON, Antoine; GROS, Frédéric; PECH, Thierry. Punir em democracia - e a justiça será. Lisboa: Instituto Piaget, 2001.

GIONGO, R.C.P. Justiça restaurativa e violência doméstica conjugal: aspectos da resolução do conflito através da mediação penal. 2009. 122 f. Dissertação (Mestrado em Ciências Criminais) - Programa de Pós-Graduação em Ciências Criminais, PUCRS. Porto Alegre, 2009.

LARRAURI, Elena. Mujeres y sistema penal. Violência doméstica. Montevideo: B de F, 2008.

MARSHALL, Tony. The evolution of Restorative Justice in Britain. European Journal on Criminal Policy Research, v. 4, n. 4. Heidelberg: Springer, 1996.

MEDEIROS, Carolina Salazar L'armée Queiroga de. Reflexões sobre o punitivismo da Lei "Maria da Penha" com base em pesquisa empírica numa Vara de violência doméstica e familiar contra a mulher do Recife. 2015. 158f. Dissertação (Mestrado em Direito) Universidade Católica de Pernambuco, Recife.

MELlO, Marília Montenegro Pessoa de. Lei Maria da Penha: uma análise criminológicocrítica. 1.ed. Rio de Janeiro: Revan, 2015.

MORRIS, Alisson. Criticando os críticos: uma breve resposta aos críticos da justiça restaurativa. In: SLAKMON, C. et al. (orgs.). Justiça restaurativa. Brasília - DF: Ministério da Justiça e Programa das Nações Unidas para o Desenvolvimento - PNUD, 2005, pp. 439464. 
NADER, Laura. Harmonia coercitiva: a economia política dos modelos jurídicos. Revista Brasileira de Ciências Sociais. São Paulo, v. 9, n. 26, out. 1994. Disponível em: https://www.anpocs.com/index.php/publicacoes-sp-2056165036/rbcs/211-rbcs-26. Acesso em: 03 fev. de 2021.

ORGANIZAÇÃO DAS NAÇÕES UNIDAS - ONU. Resolução 2002/12. Dispõe sobre princípios básicos para utilização de programas de justiça restaurativa em matéria criminal. Disponível em: http://www.juridica.mppr.mp.br/arquivos/File/MPRestaurativoEACulturadePaz/Material_de_ Apoio/Resolucao_ONU_2002.pdf. Acesso em: 03 fev.de 2021.

OXHORN, Philip; SLAKMON, Catherine. Microjustiça, desigualdade e cidadania democrática: a construção da sociedade civil através da justiça restaurativa no Brasil. In: BASTOS, Márcio Thomaz; LOPES, Carlos; RENAULT, Sérgio Rabello Tamm (orgs.). Justiça restaurativa: coletânea de artigos. Brasília: MJ e PNUD, 2005.

PADÃO, Jacqueline. Justiça restaurativa e violência doméstica. 2019. 138f. Dissertação (Mestrado em Direitos) - Programa de Pós-Graduação em Direito do Centro Universitário Ritter dos Reis. Canoas, 2019. No prelo.

PALLAMOLLA, Raffaela da Porciuncula. A construção da justiça restaurativa no Brasil e o protagonismo do Poder Judiciário: permanências e inovações no campo da administração de conflitos. 2017. 286f. Tese (Doutorado em Ciências Sociais) - Programa de Pós-Graduação em Ciências Sociais, PUCRS. Porto Alegre, 2017. No prelo.

PALLAMOLLA, Raffaella da Porciuncula. Justiça restaurativa: da teoria à prática. São Paulo: IBCCRIM, 2009.

PELIKAN, Christa; HOFINGER, Veronika Hofinger. An interactional approach to desistance: expanding desistance theory based on the Austrian mediation practice in cases of partnership violence. Restorative Justice, v. 4, ed. 3, pp. 323-344, 2016.

PIRES, Álvaro P. A teoria da "racionalidade penal moderna" e os desafios da justiça juvenil. [Entrevista concedida a] Bruna Gisi, Juliana Tonche, Marcos Cesar Alvarez e Thiago Oliveira. PLURAL, Revista do Programa de Pós-Graduação em Sociologia da USP, São Paulo, v. 24, pp. 124-160, 2017.

PRANIS, Kay; WATSON, Carolyn Boyes. No coração da esperança. Guia de práticas circulares: o uso de círculos de construção da paz para desenvolver a inteligência emocional, promover acura e construir relacionamentos saudáveis. Porto Alegre: Tribunal de Justiçado Estado do Rio Grande do Sul, Departamento de Artes Gráficas, 2011.

ROSENBLATT, F; MELLO, M. M.P. O uso da Justiça restaurativa em casos de violência de gênero contra a mulher: potencialidades e riscos. In: OLIVEIRA, L. et al. (orgs.). Para além do Código de Hamurabi: estudos sociojurídicos. Recife: ALID, 2015.

SOZZO, Máximo. "Traduttore traditore": traducción, importación cultural e historia del presente de la criminologia em América Latina. Cuadernos de Doctrina y Jurisprudencia Penal, Buenos Aires, Villela, año VII, n. 13, 2001, pp. 353-431. 